\title{
Targeted and non-targeted analysis of organic compounds of moderate polarity in water using liquid chromatography-time of flight mass spectrometry in all ion mode with particular reference to analysis of pesticides
}

\author{
Padma Marwah \\ Center for Coastal Studies, Texas A\&M University, Corpus Christi, TX 78412 , USA \\ Current Address: 10F Gounlloy, Nuvem, South Goa-403713, India \\ Ashok K. Marwah* \\ 10F Gounlloy, Nuvem, South Goa-403713, India \\ Paul V. Zimba \\ Center for Coastal Studies, Texas A\&M University, Corpus Christi, TX 78412, USA \\ Sue D'antonio \\ Agilent Technologies, 1834 TX-71 W, Cedar Creek, TX 78612, USA \\ ${ }^{*}$ Corresponding author. E-mail: akmarwah@gmail.com
}

\author{
Article Info \\ https://doi.org/10.31018/ \\ jans.v12i3.2309 \\ Received: June 6, 2020 \\ Revised: July 5, 2020 \\ Accepted: July 13, 2020
}

\section{How to Cite}

Marwah, P. et al. (2020). Targeted and non-targeted analysis of organic compounds of moderate polarity in water using liquid chromatography-time of flight mass spectrometry in all ion mode with particular reference to analysis of pesticides. Journal of Applied and Natural Science, 12(3): 299 - 311. https://doi.org/10.31018/jans.v12i3.2309

\begin{abstract}
We have developed a novel yet efficient method for the multi residue analysis of organic compounds of diverse polarities in water using Liquid Chromatography-Time of Flight mass spectrometry (LC-MS-TOF) equipped with a jet stream Electrospray ionization (ESI) source. Use of three different fragmentor voltages (low, medium and high) enabled the qualitative and quantitative analysis of a diverse range of targeted organic compounds in environmental waters. No prior optimization of compounds being quantified was required, the limiting factors were ionization behaviour of compounds under conditions of ESI and good chromatography. Same data file could be subjected to repeated post-run data analysis to figure out the presence of nontargeted compounds, including designer drugs if any. The technique has been illustrated with reference to a group of pesticides having diverse chromatographic and ionization behaviours. The optimized Solid Phase Extraction (SPE) followed by method validation yielded a robust yet simple quantitative method for a group of fourteen pesticides. We were able to achieve quantitation at $10 \mathrm{ng} / \mathrm{L}$ or lower depending upon ionization behaviour of substrates against the usual regulatory requirement of $1000 \mathrm{ng} /$ L. The method was used for targeted and non-targeted detection of pesticides in Nueces estuary waters, TX, USA, and several untargeted pesticides, pharmaceuticals and personal care products were identified.
\end{abstract}

Keywords: Liquid Chromatography, Organic compound, Pesticides, Qualitative and Quantitative analysis

\section{INTRODUCTION}

Liquid chromatography-mass spectrometry is being increasingly used for the analysis of organic compounds. Advent of soft ionization techniques coupled with tremendous technological advancements, have made mass spectrometry an indispensable tool in biological and chemical sciences (Siuzdak, 2003). Mass measurements with an accuracy of a few parts per million or better have made unambiguous identifications and database searches a desktop reality (GagoFerrero et al., 2019) resulting in simultaneous analysis of targeted as well as non-targeted compounds. Use of mass spectrometry is not limited to any class of group of compounds but is a slave of the compound's ability to ionize under a set of experimental conditions (Holcapek and Byrdwell, 2017). Pesticides have been widely used throughout the world to increase agricultural productivity, but for a mass spectrometrist, they are a group of compounds of vastly different structures and chemistries often posing challenging problems of poor chromatography and ionization.

Pesticides belong to more than a hundred different classes with benzoylureas, carbamates, organophosphorus compounds, pyrethroids, sulfonylureas, and 
triazines being some of the most important groups (Sidhu et al., 2019; Latrous El Atrache et al., 2013). The physicochemical and chromatographic characteristics of pesticides differ considerably. There are acidic, basic and neutral pesticides. Some compounds contain halogens, others phosphorous, sulfur, or nitrogen or a combination thereof. A number of compounds are volatile or semi-volatile. This diversity causes serious problems in the development of a "universal" analytical method having a widest possible scope.

Gas chromatography (GC) and liquid chromatography (LC) have been utilized for the development of specific and sensitive methods for the determination of pesticides (Alder et al., 2006, Elbashir and Aboul-Enein, 2017). Pesticides and other chemicals have been traditionally quantified using triple quadrupole mass spectrometers (LCMS-QQQ, Botero-Coy et al., 2011). The triple quadrupole mass spectrometer allows for increased sensitivity and specificity yielding lower detection and quantitation limits but only for the targeted optimized compounds, and do suffer from major disadvantages such as lack of accurate mass measurements and inability to perform non-targeted analysis of non-optimized organic compounds. LCMS-QQQ demands elaborate sometimes tedious and lengthy method development since mass-to-charge $(\mathrm{m} / \mathrm{z})$ ratios of precursor ions as well as of fragments ions must be decided and optimized in advance for every compound. This can be very time consuming if analysis of a broad spectrum of compounds is the demand of the day. Any compound/designer drug, their metabolites and degradation products, which have not been optimized before-hand, escape analysis (Botitsi et al., 2010).

Therefore, there is an urgent need for research studies on the simultaneous analysis of targeted and nontargeted pesticides. In order to do such studies, the use of multiple instruments (Masia et al., 2013) such as LC/MS TOF/QTOF for accurate mass measurement (Amelin and Andoralov, 2015; Arsand et al. 2018, Rousis et al., 2017) and LC/MS ion trap/orbitrap (Cotton et al. 2016) or LC/MS/MS for fragmental (MS/ MS) analysis are being increasingly used (Primel et al., 2012). Currently, MS-TOF system operated in All Ion MS/MS mode delivers an accurate mass of compounds (better than $5 \mathrm{ppm}$ accuracy) along with fragment analysis of compounds at varying fragmentor voltages enabling characterization of targeted and non -targeted analytes in complex environmental matrices using a single instrument and in single acquisition run and is more cost-effective than buying a triple quadrupole instrument and at the same time delivers accurate mass for the fragments resulting in better reliability of data analysis and database searching.

The aim of this study was to develop and validate an efficient, robust and rugged method for the analysis of organic compounds with particular reference to pesticides in waters using liquid chromatography-time of flight mass spectrometer in an all ion MS/MS mode. A group of fourteen targeted pesticides of varied properties, representing a broad range of organic compounds, were selected for the purpose of quantitation and validation. Sample preparation is the major step to develop a good analytical method. The targeted pesticides represented quite a wide polarity response from polar to non-polar compounds, and some were basic and amphoteric in nature, some were chlorinated organic compounds, some were non-volatile to semivolatile, and last but not the least good to poor ionizers. Hence, our goal was to develop an optimized solid -phase extraction procedure to provide consistently high recoveries and precision for the pesticides, including semi-volatile liquid pesticides such as molinate, malathion and dimethoate.

\section{MATERIALS AND METHODS}

Unlike a triple quadrupole mass spectrometer, neither previous compound information (m/z precursor/ fragment ions) nor any optimization of precursor and fragment ions was required prior to acquisition; the only requirement being the presence of an ionizing group in the molecule and easier the ionization in electrospray mode $(\mathrm{ESI})$ better the sensitivity. The data was acquired at three fragmentor voltages (all lon MS/ MS) simultaneously and analysis of targeted pesticides and non-targeted organic compounds, ionizable under experimental conditions, was achieved by identifying product ions, with the help of fragment analysis and commercial databases searches (Gao et al., 2019; Lee et al., 2020).

A pesticide reference standard solution (Agilent Technologies, $100 \mu \mathrm{g} / \mathrm{ml}$ ) contained fourteen pesticides having wide polarity range from polar to non-polar. Ammonium formate, formic acid, trifluoroacetic acid, methanol, ethanol, isopropanol and acetonitrile were all HPLC grade or better (Fisher scientific, (Pittsburgh, PA, USA). Milli-Q-synergy ultra-pure water (18.25 $\pm 0.05 \mathrm{M} \Omega-\mathrm{cm}$, Millipore, USA) was used throughout the study. Environmental waters from Nueces river and estuary were collected at different times of the year. Solid-phase extraction (SPE) cartridges (Oasis-HLB, $6 \mathrm{cc}$ ) were obtained from Waters Corporation (MA, USA). For river water filtration, glass microfiber filters $(1 \mu \mathrm{m})$, were purchased from Millipore. Instrumentation: HPLC-MS-TOF system (Agilent Technologies Inc. Palo Alto, CA, USA) was used for method development, validation, and quantitation of pesticides. The 1290 series HPLC comprised of a binary pump with an online degasser, a heated column compartment, autosampler with thermostat, and a di- 
ode array UV detector. MS-TOF (6230 series) system was equipped with Agilent jet-stream (AJS), a dual spray ESI detector. Data were acquired and processed using Agilent's Mass Hunter software (version B.07.00).

\section{Analytical conditions}

HPLC: Chromatography was performed on a Poroshell-120 EC $\mathrm{C}_{18}$ column $(2.1 \times 150 \mathrm{~mm}, 2.7 \mu \mathrm{m}, 80$ $\AA$, Agilent Technologies Inc. CA, USA) protected by an Agilent EC $2.7 \mu \mathrm{m} \mathrm{C}_{18}$ guard column, $(3 \times 5 \mathrm{~mm})$ at a flow rate of $0.5 \mathrm{ml} / \mathrm{min}$ and column temperature of $50{ }^{\circ} \mathrm{C}$. The injected sample volume was $10 \mathrm{ml}$. A water-95\% methanol linear gradient: $(95: 05, \mathrm{v} / \mathrm{v})$ at time $t=0$ to $t=0.5$, and $5: 95$ at $t=8 \mathrm{~min}$ to $10 \mathrm{~min}$ was used with a post run time of $4 \mathrm{~min}$ (dwell volume for 1290 pump is $<100 \mu \mathrm{l})$ ). Ammonium formate $(2 \mathrm{mM})$, formic acid $(0.1 \%)$ trifluoroacetic acid (10 ppm), and heptafluorobutyric acid (0.2 ppm) were added to water and 95\% methanol (Marwah et al. 2020).

MS-TOF: The best suited dual electrospray (dual ESI) parameters for Agilent Jet stream electrospray ionization chamber (AJS) were: drying gas $\left(\mathrm{N}_{2}\right) 8 \mathrm{~L} / \mathrm{min}$, gas temperature $325^{\circ} \mathrm{C}$, nebulizer $35 \mathrm{psi}$, sheath gas temperature $350{ }^{\circ} \mathrm{C}$, sheath gas flow $11 \mathrm{~L} / \mathrm{min}$, Vcap 2500 $\mathrm{V}$, nozzle voltage $1000 \mathrm{~V}$. Analysis was carried out in all ion mode (positive ion) using three different fragmentor voltages $(150 \mathrm{~V}, 200 \mathrm{~V}, 250 \mathrm{~V}$; All Ion MS/MS analysis)) in a single time segment. Data collection rate was six spectra/min (2170 transients/spectrum). Dual ESI, with its reference nebulizer, provided a continuous flow of reference ions (121.0508 and 922.0098) during the run. MS-TOF was tuned (mass range $100-1700$ in $2 \mathrm{GHz}$ mode) once a month and calibrated (mass range 100-1700 at $2 \mathrm{GHz}$ mode) always before acquiring data. Spray chamber was cleaned before running a batch analysis, especially after every batch of environmental water samples using propanol-2:water (1:1). Nebulizer needles (sample and reference) were cleaned weekly by sonicating in propanol-2:water (1:1).

Preparation of standard solutions: The standard stock solution of fourteen pesticides (100 $\mu \mathrm{g} / \mathrm{ml}$ each) was diluted with methanol-water $(4: 1)$ to obtain working stock standard solutions $(500 \mathrm{ng} / \mathrm{ml})$. Seven Calibration solutions of $(1000,500,250,125,50,25,12.5$ $\mathrm{ng} / \mathrm{L}$ ) and two quality control samples (100 and 750 $\mathrm{ng} / \mathrm{L})$ were prepared in MQ-water from working stock solution.

Solid-phase extraction: For the solid-phase extraction of the samples (process blanks, calibration samples, quality control samples and river water samples), Oasis HLB cartridges ( $200 \mathrm{mg}, 6 \mathrm{ml}$, Waters) were activated and conditioned with $5 \mathrm{ml}$ methanol and $5 \mathrm{ml}$ water. Appropriate quantity of the sample was added to $1 \mathrm{~L}$ water matrix in $1000 \mathrm{ml}$ polypropylene bottle.
Formic acid $(0.05 \mathrm{ml})$ was added, and samples were hand-shaken for $10 \mathrm{~s}$. The water layer was applied directly to wet preconditioned cartridge at a flow-rate of $10 \mathrm{ml} \mathrm{min}{ }^{-1}$, using siphon (1 $\mathrm{m}$ height) and vacuum $(\sim 50 \mathrm{~mm}$ of $\mathrm{Hg})$. The loaded cartridge was washed one time with $5 \mathrm{ml}$ of $5 \%$ methanol-water (gravity pull), and pesticides were eluted with methanol $(0.5+0.5+2+0.5 \mathrm{ml})$. After every addition, methanol was allowed to stay in the cartridge for $5 \mathrm{~min}$. Finally, methanol was recovered from the cartridge under suction and eluted methanol diluted to $10 \mathrm{ml}$ with water, and $10 \mu$ l was injected on column.

Preparation of environmental water samples for the LC-MS analysis: River (Nueces) water samples (1L) were filtered twice through $1.2 \mu \mathrm{m}$ (Whatmann, 47 $\mu \mathrm{m}$ GF/C grade) glass microfibre filter protected with a glass fibre prefilter (Merck Millipore), followed by a 1 $\mu \mathrm{m}(\mathrm{HACH}$ grade $\mathrm{A} / \mathrm{E})$ glass microfiber filter. Formic acid $(0.05 \%)$ was added to the filtered river water sample and then passed through HLB 6 cc preconditioned cartridge using vacuum $(\sim 10 \mathrm{~mm}$ of $\mathrm{Hg})$.

\section{RESULTS AND DISCUSSION}

Solid-phase extraction (SPE) is probably the most widely used sample preparation technique in LC-MS analysis of compounds of varying chemistries and diverse matrices including samples from environmental waters (Kharbouche et al., 2019; Sabik et al. 2000). It is not always necessary to evaporate the solvent to achieve the desired enrichment factor of analytes (Tankiewicz et al., 2011).

The present procedure demanded a delicate balance of extraction as well as chromatographic and mass spectrometric parameters so as to identify and quantify a variety of compounds with varied properties (polar, non-polar, amphoteric, acidic, basic, solids, semisolids, liquids, good ionizers and poor ionizers). This group consisted of aminocarb, a highly basic N,Ndimethyl derivative which makes it elute early, ionize nicely but also causes peak tailing. Thiabendazole and imazapyr are both basic by virtue of being nitrogen heterocycles and eluted early with reasonable sensitivity. Carbofuran, a benzofuran derivative is a poor substrate for ESI-LC-MS due to absence of good proton acceptors in the molecule. Phospho-pesticides viz. malathion (boiling point $156^{\circ} \mathrm{C}$ ), dimethoate (boiling point $117^{\circ} \mathrm{C}$ ) and molinate, an azepane carbothioate, (boiling point $136.5^{\circ} \mathrm{C}$ at $10 \mathrm{~mm}$ of $\mathrm{Hg}$ ) were challenging candidates for extraction from the matrix as well as ionization in ESI-MS by virtue of being semi-volatile, and did not permit evaporation of solvent after solidphase extraction. Also studied were glyphosate, a widely used water-soluble herbicide, and its main metabolite aminomethylphosphonic acid (AMPA), highly polar, amphoteric and difficult to retain on small col- 


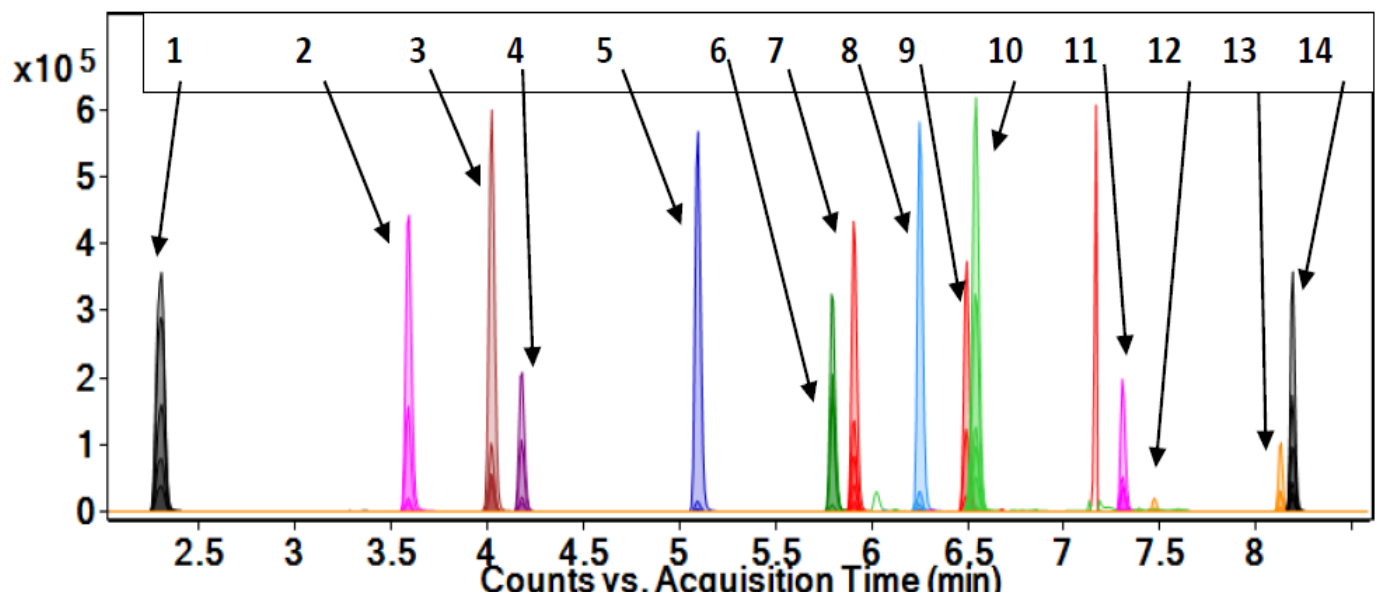

Fig. 1. All ion LC-MS-TOF analysis of fourteen representative pesticides under three fragmentor voltages. Fragments of the parent ion can be seen under the peaks (cf. Fig.2). Complete details are given in experimental section. 1: Aminocarb; 2: Thiabendazole, 3: Imazapyr; 4: Dimethoate; 5: Metoxuron; 6: Carbofuran; 7: Metosulam; 8: Imazalil; 9: Atrazine; 10: Metazachlor; 11: Malathion; 12: Molinate; 13: Diazinon and 14: Pyraclostrobin.

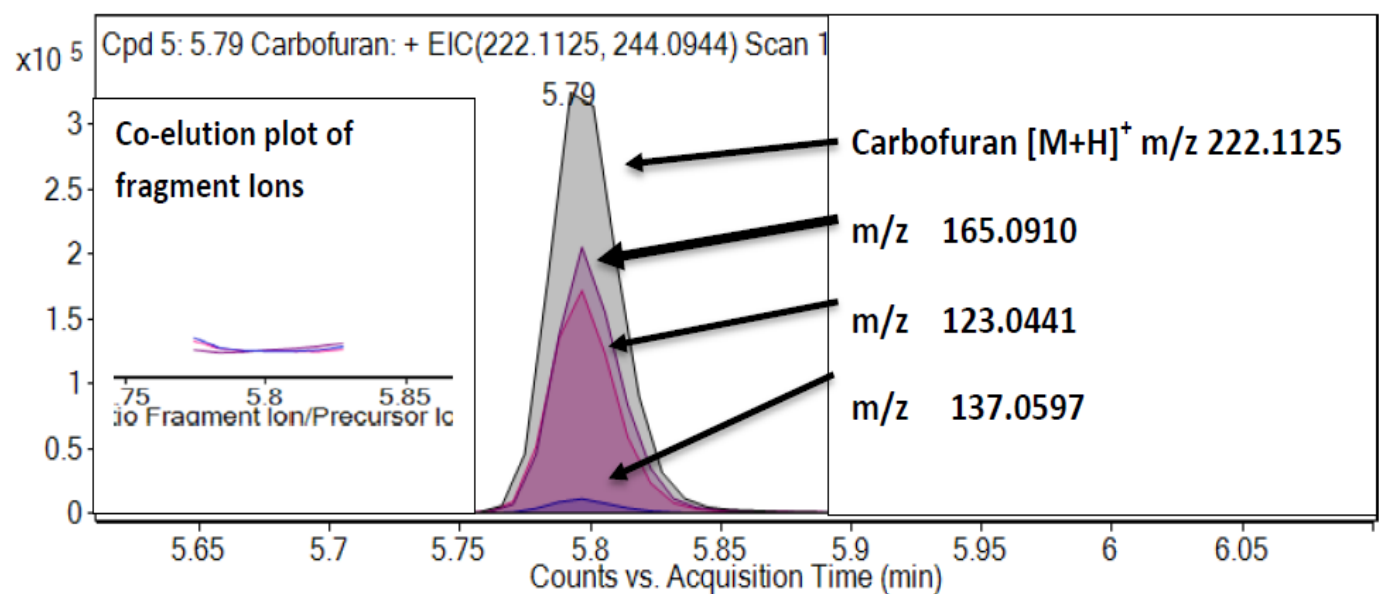

Fig. 2. All ion fragmentation (pseudo MS/MS) of Carbofuran using fragmentor voltage of 150, 200 and $250 \mathrm{~V}$ during a single acquisition run. Co-elution plot of fragment ions clearly indicates that all the ions belong to the same parent ion which can be further confirmed by the fragmentation pattern.

umn molecules (Jaikwang, 2020). These two compounds eluted with solvent front under initial chromatographic conditions ( $5 \%$ methanol in water) necessitating ion-exchange chromatography and are not included in this study. LC-MS analysis was carried out in positive ion mode using electrospray ionization. The use of heptafluorobutyric acid, trifluoroacetic acid, formic acid and ammonium acetate as mobile phase additives resulted in sharp, symmetrical peaks (Fig. 1 and Fig. 2), the almost total absence of metal ion adducts (Fig. 3) and improved sensitivity (Marwah and Marwah, 2020).

This studied was conducted using all ion MS/MS mode (pseudo MS/MS) of the TOF system (Marwah and Marwah, 2013). All lons MS/MS mode alternates between low, medium and high energy scans during a single acquisition run: high energy scans created fragments while low energy scans preserved the precursor ions. Precursor ions and corresponding fragments are extracted from the data using an accurate mass data- base, and the co-elution plot indicated the quality of correlation between precursor and fragment ions for each compound (Fig. 2). The use of qualifier ion(s) (fragments and or isotopic peaks particularly because of one or more chlorine atoms) effectively ruled out interference from matrix components, degradation products, impurities and isobaric compounds. The qualifier and quantifier ions for the fourteen pesticides used in this study are given in Table 1 . The ${ }^{37} \mathrm{Cl}$ isotope of chloro compounds (atrazine, metoxuron, metazachlor and pyraclostrobin) were used as qualifier ions and presence of two chlorine atoms in the molecule (imazalil and metosulam) further improved the sensitivity of qualifier peak.

System Suitability: The suitability of the LC-MS-TOF system was evaluated by the analysis of a mixture of fourteen pesticides. The chromatograms were evaluated for peak widths at half height (FWHM), mass accuracy $(\mathrm{ppm})$, reproducibility of retention time (\%RSD) and signal-to-noise ratio (S/N). LC-MS system was 

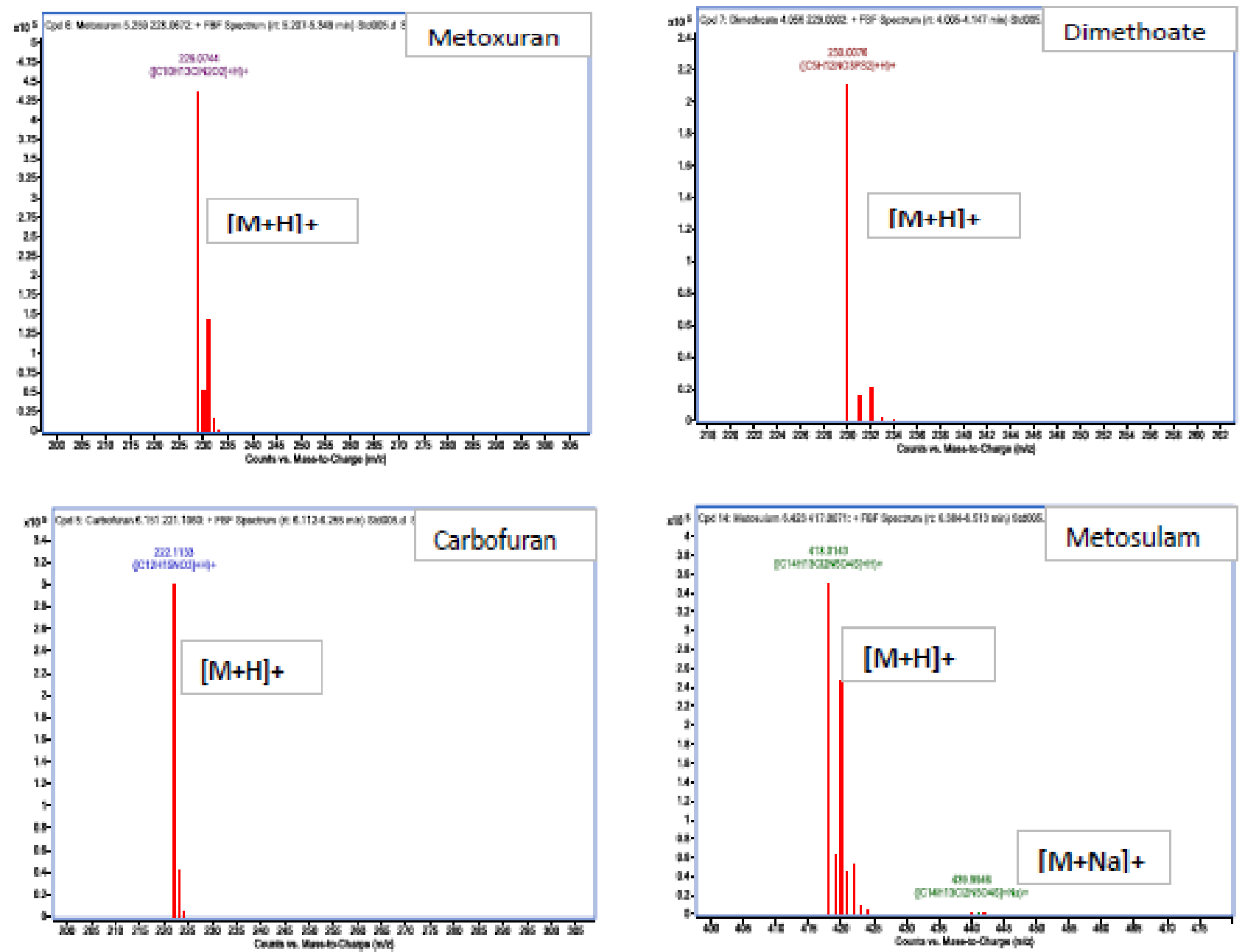

Fig. 3. Mass spectrum of Metoxuran, Dimethoate, Carbofuran and Metosulam obtained using a cocktail of formic acid, trifluoroacetic acid, heptafluorobutyric acid and ammoniumacetae in water-methanol gradient. Near absence of [M+Na] ${ }^{+}$ and total absence of $[M+K]^{+}$adducts was obseved. Complete $L C-M S$ details under experimental section.

considered to be performing suitably if $\mathrm{S} / \mathrm{N}$ ratio was not less than 100 for $125 \mathrm{ng} / \mathrm{L}$ concentration, mass accuracy was better than $5 \mathrm{ppm}$, peak widths did not exceed $0.04 \mathrm{~min}$, and RSD of retention times $(n=4)$ of pesticides did not exceed $1 \%$.

Specificity: Specificity is the ability of the procedure to measure the analyte of interest accurately and specifically in the presence of closely related structures, impurities, degradation products, and other components that could be expected to be present in the matrix. The use of the time of flight mass spectrometer (LCMS-TOF) made it possible to differentiate between any overlapping compounds of different molecular weights. Mass accuracy of 5 ppm or better (mostly 1-2 ppm) was routinely achieved. Factors such as regular tuning, use of real time reference ions, ultra-low dwell volume $(<100 \mu \mathrm{l})$ of the system among others were instrumental in developing a highly reproducible and robust chromatographic method. Same retention times could be reproduced day after day with less than $0.3 \%$ RSD ( $n=225$; Table 2) with nice sharp peaks (FWHM
$0.03 \mathrm{~min})$. Fig. 1 shows all ion LC-MS-TOF analysis of fourteen representative pesticides under three fragmentor voltages. Fragments of the parent ion could be seen under the peaks (Fig. 2). All ion fragmentation (pseudo MS/MS) of Carbofuran using fragmentor voltage of 150,200 and $250 \mathrm{~V}$ during a single acquisition run is shown in Fig. 2. Co-elution plot of fragment ions clearly indicated that all ions belonged to the same parent ion. This precluded the possibility of isobaric compounds from interfering unless the fragmentation pattern was exactly the same. The use of qualifier ion (s) (fragments and or isotopic peaks such as those originating from the presence of one or more chlorine atoms) effectively ruled out interference from matrix components, degradation products and impurities as well as from isobaric compounds. It may be mentioned that for a compound to interfere in the present assay following requirements must be met: a) it should have same accurate mass; b) it should have same quantifier ion; c) it should have same qualifier ion(s) and d) it should have same retention time. It is extremely diffi- 
Table 1. Qualifier and quantifier ions for the representative pesticides.

\begin{tabular}{|c|c|c|c|c|c|c|c|c|}
\hline \multirow[t]{2}{*}{ Name } & \multirow[t]{2}{*}{ Formula } & \multirow[t]{2}{*}{ Mass } & \multirow[t]{2}{*}{ RT } & \multirow{2}{*}{$\frac{\text { Quantifier }}{[\mathrm{M}+\mathrm{H}]+}$} & \multirow{2}{*}{$\frac{\text { Qualifier }}{\text { I }}$} & \multirow{2}{*}{$\begin{array}{l}\text { Qualifier } \\
\text { II }\end{array}$} & \multirow{2}{*}{$\begin{array}{l}\text { Qualifier } \\
\text { III }\end{array}$} & \multirow{2}{*}{$\begin{array}{l}\text { Qualifier } \\
\text { IV }\end{array}$} \\
\hline & & & & & & & & \\
\hline Aminocarb & $\mathrm{C} 11 \mathrm{H} 16 \mathrm{~N} 2 \mathrm{O} 2$ & 208.1218 & 2.31 & 209.1285 & 137.0835 & 152.1070 & 122.0600 & 136.0757 \\
\hline Atrazine & C8 H14 Cl N5 & 215.0948 & 6.50 & 216.1010 & 218.0982 & 174.0541 & 104.0010 & ND \\
\hline Carbofuran & $\mathrm{C} 12 \mathrm{H} 15 \mathrm{~N} \mathrm{O} 3$ & 221.1061 & 5.79 & 222.1125 & 165.0910 & 123.0441 & 137.0597 & ND \\
\hline Diazinon & $\mathrm{C} 12 \mathrm{H} 21 \mathrm{~N} 2 \mathrm{O} 3 \mathrm{P} \mathrm{S}$ & 304.1019 & 8.13 & 305.1083 & 169.0794 & 153.1022 & 249.0454 & 277.0770 \\
\hline Dimethoate & C5 H12 N O3 P S2 & 229.0004 & 4.19 & 230.0069 & 170.9698 & 124.9821 & 198.9647 & ND \\
\hline Imazalil & $\mathrm{C} 14 \mathrm{H} 14 \mathrm{Cl} 2 \mathrm{~N} 2 \mathrm{O}$ & 296.0493 & 6.25 & 297.0556 & 299.0528 & 158.9763 & ND & ND \\
\hline Imazapyr & $\mathrm{C} 13 \mathrm{H} 15 \mathrm{~N} 3 \mathrm{O} 3$ & 261.1121 & 4.03 & 262.1186 & 220.0717 & 149.0346 & 217.0972 & 202.0611 \\
\hline Malathion & $\mathrm{C} 10 \mathrm{H} 19 \mathrm{O} 6 \mathrm{P}$ S2 & 330.0368 & 7.31 & 331.0433 & 127.0390 & 124.9821 & 285.0015 & \\
\hline Metazachlor & C14 H16 Cl N3 O & 277.0990 & 6.54 & 278.1055 & 280.1029 & 134.0964 & 105.0964 & 210.0680 \\
\hline Metosulam & $\mathrm{C} 14 \mathrm{H} 13 \mathrm{Cl} 2 \mathrm{~N} 5 \mathrm{O} 4 \mathrm{~S}$ & 417.0071 & 5.91 & 418.0138 & 420.0110 & 176.9931 & 174.9944 & 354.0519 \\
\hline Metoxuron & $\mathrm{C} 10 \mathrm{H} 13 \mathrm{Cl} \mathrm{N} 2 \mathrm{O} 2$ & 228.0674 & 5.10 & 229.0738 & 231.0711 & 156.2090 & ND & ND \\
\hline Molinate & C9H17 NOS & 187.1033 & 7.47 & 188.1104 & 126.0913 & ND & ND & ND \\
\hline Pyraclostrobin & $\mathrm{C} 19 \mathrm{H} 18 \mathrm{Cl}$ N3 O4 & 387.0980 & 8.19 & 388.1059 & 390.1037 & 194.0812 & 163.0628 & 164.0706 \\
\hline Thiabendazole & $\mathrm{C} 10 \mathrm{H} 7 \mathrm{~N} 3 \mathrm{~S}$ & 201.0368 & 3.60 & 202.0433 & 175.0324 & 131.0604 & 143.0604 & ND \\
\hline
\end{tabular}

ND : Not detected

cult for another compound to have all the four same characteristic features, and therefore it is unlikely that another compound will interfere in the present assay. A compound was deemed to be uniquely identified when at least three features were found to be present since a few compounds neither produced good fragments nor had abundant isotopic peaks. Therefore, it is reasonably safe to conclude that the present water method is a highly specific method. The developed method was able to assay pesticides with a high degree of accuracy and precision in the presence of impurities, isobaric compounds, degradation products and matrix components.

Linearity and range: Calibration curves consisting of a blank sample (matrix sample without pesticides) and seven calibration samples $(0,12.5,25,50,100,250$, $500,1000 \mathrm{ng}$ of fourteen different pesticides in 1000 $\mathrm{ml}$ of MQ-water) along with two quality control samples (125 and $750 \mathrm{ng} / 1000 \mathrm{ml}$ of MQ-water) were plotted in the present study. Calibration curves $(n=23$, Table 3) were generated under different conditions to ascertain precision, accuracy, ruggedness, and robustness of the method. The range studied (12.5 to $1000 \mathrm{ng}$ of pesticides in $1000 \mathrm{ml} \mathrm{MQ}$-water) was found to be linear and use of $1 / y$ weightage gave reproducible results day after day under the same processing conditions and parameters. For the calibration curves $(y=m x+c)$ plotted for the determination of fourteen pesticides, the average correlation coefficient was found to be between 0.995 to 0.999 (\% RSD 0.06 $-0.84 ; n=23)$. There was no significant difference between calibration curves plotted under different conditions. Fig. 4 shows extracted ion chromatograms (EIC) showing all nine calibration levels of the four- teen representative pesticides.

Extraction recoveries: The extraction recoveries of fourteen pesticides from water spiked with pesticides, were determined by comparing areas of pesticides peak $[\mathrm{M}+\mathrm{H}]^{+}$, recovered from water spiked with 1000 ng concentration of pesticides in one liter of water, processed by assay procedure versus area of pesticides peak $[\mathrm{M}+\mathrm{H}]^{+}$, obtained from pure chemical standards of same concentrations. Extraction recoveries were calculated as:

$\%$ Extraction Recovery $=($ Area pesticides water $/$ Area pesticides (hemical $\times 100 \quad$........Eq. 1

In which: Area pesticides water $=$ Area of pesticides in water spiked with pesticides, and Area pesticides chemical $_{\text {in }}$ $=$ Area of pesticides in a pure chemical sample.

In order to arrive at most suitable cartridge for the extraction of pesticide mixture of varying polarities, we selected a C-18 cartridge along with polymeric sorbent cartridges (Strata-X 6cc, and polymeric reversedphase sorbents Oasis HLB 6cc \& Oasis Prime HLB $6 \mathrm{cc})$. Aminocarb, the most polar pesticide among fourteen compounds studied, was partially retained by Prime HLB cartridge and was not retained by $\mathrm{C}-18$ cartridge under our extraction procedure. Imazalil and thiabendazole were also not detected when C-18 cartridges were used. Recovery of Imazalil was found to be erratic and not reproducible from water, but the addition of formic acid into water $(0.05 \% \mathrm{v} / \mathrm{v})$ resulted in good reproducible recoveries. Strata-X $6 \mathrm{cc}$ and Oasis HLB $6 c c$ cartridges were found to give good recoveries of all the pesticides used in the present study. The extraction recovery of fourteen pesticides from water, determined by comparing areas of pesticides peak recovered from water spiked with known amounts of 
Table 2. Reproducibility of the retention times of the fourteen pesticides.

\begin{tabular}{llcc}
\hline Name & $\begin{array}{l}\mathbf{t}_{\mathbf{R}} \\
(\mathbf{m i n})\end{array}$ & $\begin{array}{c}\text { Study period } \\
\mathbf{t}_{\mathbf{R}}(\mathbf{\%} \mathbf{R S D}) \\
(\mathbf{n = 2 2 5})\end{array}$ & $\begin{array}{c}\text { intra run } \\
\mathbf{t}_{\mathbf{R}}(\mathbf{\%} \mathbf{R S D}) \\
(\mathbf{n = 4 5})\end{array}$ \\
\hline Aminocarb & 2.31 & 0.30 & 0.12 \\
Atrazine & 6.49 & 0.07 & 0.03 \\
Carbofuran & 5.80 & 0.06 & 0.02 \\
Diazinon & 8.12 & 0.05 & 0.01 \\
Dimethoate & 4.19 & 0.06 & 0.05 \\
Imazalil & 6.24 & 0.07 & 0.01 \\
Imazapyr & 4.03 & 0.07 & 0.03 \\
Malathion & 7.30 & 0.05 & 0.00 \\
Metazachlor & 6.54 & 0.05 & 0.00 \\
Metosulam & 5.91 & 0.04 & 0.01 \\
Metoxuron & 5.10 & 0.08 & 0.04 \\
Molinate & 7.47 & 0.03 & 0.02 \\
Pyraclostrobin & 8.19 & 0.06 & 0.01 \\
Thiabendazole & 3.59 & 0.18 & 0.05 \\
\hline
\end{tabular}

Table 3. Inter batch and Intra batch reproducibility of the calibration curve.

\begin{tabular}{lllll}
\hline \multirow{2}{*}{ Name } & \multicolumn{2}{c}{ Inter-batch } & \multicolumn{2}{c}{ Intra-batch } \\
\cline { 2 - 5 } & $\mathbf{m}(\% \mathbf{m} \mathbf{R} \mathbf{2} \mathbf{n}=\mathbf{2 3}$ & $\mathbf{r}^{\mathbf{2}}$ (\%RSD) & $\mathbf{m}$ (\%SD) $\mathbf{n = 5}$ & $\mathbf{r}^{2}$ (\%RSD) \\
\hline Aminocarb & $988.8(17.1)$ & $0.9989(0.2)$ & $1109.3(1.5)$ & $0.9996(0.0)$ \\
Atrazine & $1039.4(20.3)$ & $0.9980(0.1)$ & $1196.7(0.9)$ & $0.9982(0.0)$ \\
Carbofuran & $641.4(18.8)$ & $0.9975(0.1)$ & $732.9(2.3)$ & $0.9977(0.3)$ \\
Diazinon & $382.8(30.3)$ & $0.9838(0.6)$ & $407.8(5.8)$ & $0.9846(0.6)$ \\
Dimethoate & $372.7(17.9)$ & $0.9979(0.3)$ & $426.5(1.8)$ & $0.9994(0.0)$ \\
Imazalil & $1379.2(21.5)$ & $0.9986(0.1)$ & $1606.7(1.3)$ & $0.9982(0.0)$ \\
Imazapyr & $2487.6(18.3)$ & $0.9975(0.1)$ & $2851.9(1.4)$ & $0.9972(0.0)$ \\
Malathion & $345.3(21.4)$ & $0.9976(0.1)$ & $394.4(1.7)$ & $0.9979(0.1)$ \\
Metazachlor & $549.0(20.7)$ & $0.9984(0.1)$ & $639.2(1.7)$ & $0.9986(0.0)$ \\
Metosulam & $1245.8(19.7)$ & $0.9979(0.1)$ & $1432.1(1.1)$ & $0.9978(0.0)$ \\
Metoxuron & $1288.4(21.9)$ & $0.9963(0.2)$ & $1510.2(1.5)$ & $0.9959(0.0)$ \\
Molinate & $42.6(22.2)$ & $0.9948(0.8)$ & $44.7(4.5)$ & $0.9972(0.1)$ \\
Pyraclostrobin & $520.5(29.1)$ & $0.9950(0.3)$ & $608.1(2.1)$ & $0.9959(0.2)$ \\
Thiabendazole & $2746.1(19.3)$ & $0.9971(0.1)$ & $3155.4(1.1)$ & $0.9966(0.0)$ \\
\hline
\end{tabular}

pesticides versus area of pesticides peak obtained from pure chemical standard were found to be between $82-116 \%$ (RSD 3-16\%) using Waters HLB 6c.c. cartridges (Table 4).

Accuracy and precision: Accuracy and precision of the assay were established across the range of the analytical procedure. Accuracy of the method was determined as percent recovery by the assay of known added amount of pesticides in the sample together with confidence intervals. Precision of the assay was determined as percentage relative standard deviation. The intra-run and inter run accuracy and precision of the method was evaluated by analyzing as part of a single run, replicate sets of spiked samples prepared at seven different concentrations
$(0,12.5,25,50,100,250,500,1000 \mathrm{ng}$ of fourteen different pesticides in $1000 \mathrm{ml}$ of water along with two quality control samples (125 and $750 \mathrm{ng} / 1000 \mathrm{ml}$ of water). Accuracy (Table 5) was found to be within $1.9 \%$ to $+5.1 \%$ of spiked concentrations. There was no significant difference between the accuracy at the lowest concentration (12.5 ng/L) vs. highest concentration (1000 ng/L). Inter run accuracy was found to be within $-1.7 \%$ to $+5.3 \%$ of spiked concentrations and $15 \%$ to $+3.7 \%$ at the lowest concentration $(12.5 \mathrm{ng} / \mathrm{L})$.

The intra-run as well as inter-run precision expressed as the per cent relative standard deviation (\%RSD) was found to be in single-digit (Table 5) except for diazinon $(13.8 \%)$, pyroclostrobin $(16.5 \%)$ and mollinate $(10.2 \%)$. The relatively higher \%RSD for diazinon and 


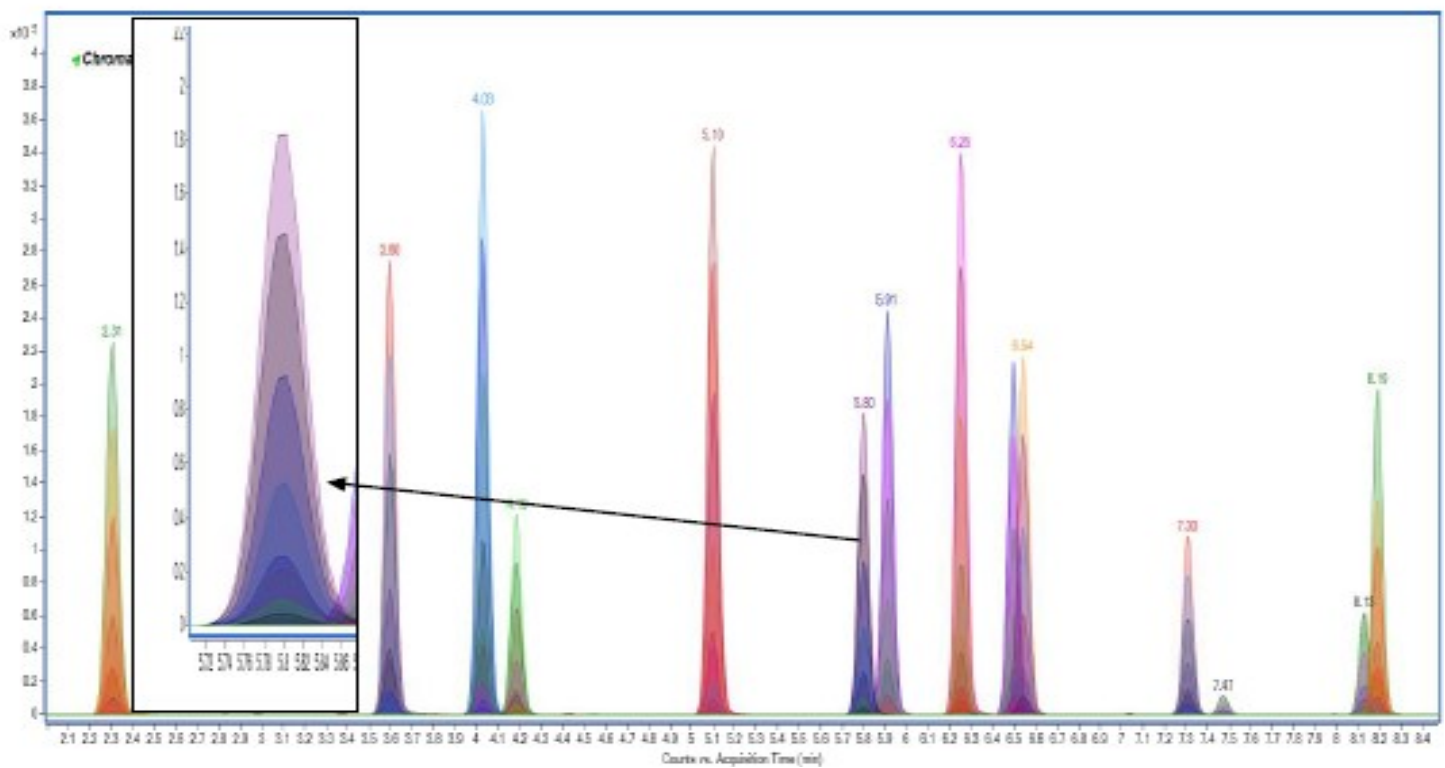

Fig. 4. Chromatograms showing all nine calibration levels of the fourteen representative pesticides. Complete analytical details are given in experimental section. 1: Aminocarb; 2: Thiabendazole, 3: Imazapyr; 4: Dimethoate; 5: Metoxuron; 6: Carbofuran; 7: Metosulam; 8: Imazalil; 9: Atrazine; 10: Metazachlor; 11: Malathion; 12: Molinate; 13: Diazinon and 14: Pyraclostrobin. Inset: Expanded view of Carbofuran calibration levels. All nine levels could be seen with appropriate zooming.

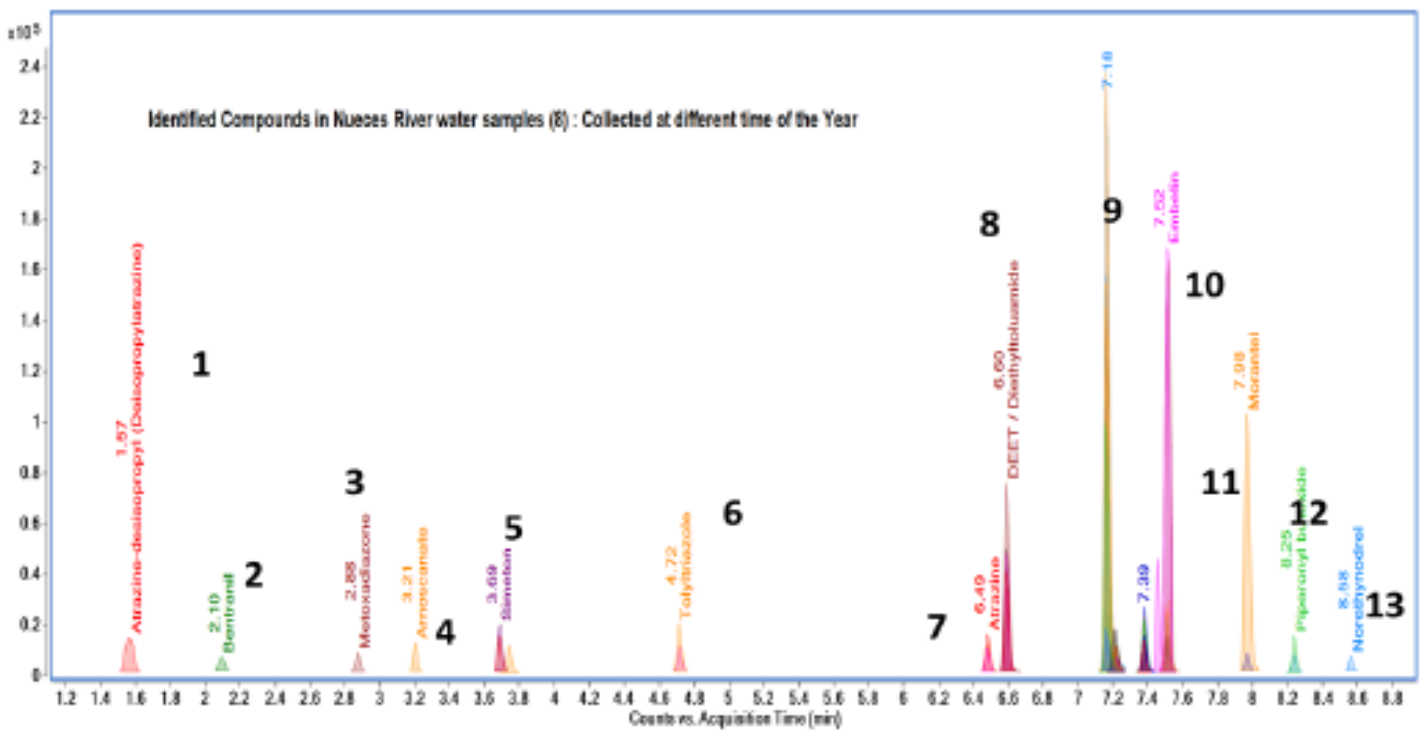

Fig.5. Non-targeted analysis of pesticides and their degradation products in the waters of Nueces river Texas, USA. 1: Deisopropylatrazine; 2: Bentranil; 3: Metoxadiazinone; 4: Arnoscanate; 5: Simeton; 6: Tolyltriazole; 7: Atrazine; 8: DEET/ Diethyltoluamide; 9: Unidentified; 10: Embelin; 11: Morantel; 12: Piperonylbutoxide; 13: Norethylnodrel. Complete analytical details are given in experimental section.

pyroclostrobin may be attributed to their non-polar nature leading to fluctuations in adsorption and elution behaviour on Oasis-HLB cartridges, whereas relatively higher \%RSD of molinate (S-ethyl 1-azapanecarbo thioate) may be ascribed to its semi-volatile behaviour under conditions of Jetstream electrospray ionization as well as poor ionization behaviour in the absence of strongly ionizing group(s) in the molecule.

Limit of detection (LOD), Limit of quantitation (LOQ) and Method detection limit (MDL): The LOD is the lowest quantity of a substance that can be distin- guished from the absence of that substance (a blank value). Typically, the blank value plus three standard deviations are established as the LOD. LOQ is the concentration at which quantitative results can be reported with a high degree of confidence. Typically, the Limit of Quantitation is determined by an empirical approach, consisting of measuring progressively more dilute concentrations of the analyte. MDL represents the minimum concentration of a substance that can be measured and reported with $99 \%$ confidence that the analyte concentration is greater than zero, and is de- 
Table 4. Extraction Recoveries of fourteen pesticides using different SPE cartridges.

\begin{tabular}{llllll}
\hline Name & $\begin{array}{c}\text { HLB, } \mathbf{6 c c} \\
\text { Average(n=5) }\end{array}$ & \%RSD & $\begin{array}{l}\text { Strata-X, 6cc } \\
\text { \% recovery }\end{array}$ & $\begin{array}{l}\text { Prime HLB } \\
\text { \% recovery }\end{array}$ & $\begin{array}{l}\mathbf{C}_{\mathbf{1 8}}, \mathbf{6 c c} \\
\text { \% recovery }\end{array}$ \\
\hline Aminocarb & 93.6 & 3.4 & 85.9 & 41.0 & $\mathrm{ND}$ \\
Atrazine & 101.1 & 5.2 & 87.1 & 99.5 & 94.1 \\
Carbofuran & 95.1 & 7.2 & 84.7 & 94.0 & 90.9 \\
Diazinon & 81.8 & 8.2 & 89.4 & 67.1 & 80.4 \\
Dimethoate & 106.0 & 4.4 & 94.9 & 106.7 & 59.9 \\
Imazalil & 116.0 & 4.8 & 108.3 & 112.9 & $\mathrm{ND}$ \\
Imazapyr & 100.7 & 3.8 & 93.0 & 102.9 & 51.3 \\
Malathion & 91.8 & 10.2 & 86.5 & 96.1 & 93.3 \\
Metazachlor & 102.3 & 5.2 & 87.0 & 99.8 & 93.4 \\
Metosulam & 96.5 & 5.0 & 84.6 & 97.1 & 92.7 \\
Metoxuron & 100.7 & 4.2 & 92.7 & 104.3 & 98.8 \\
Molinate & 100.7 & 12.7 & 96.5 & 94.8 & 101.9 \\
Pyraclostrobin & 109.7 & 16.3 & 75.7 & 137.9 & 149.3 \\
Thiabendazole & 100.2 & 4.7 & 94.3 & 91.9 & ND \\
\hline
\end{tabular}

Table 5. Accuracy and precision of the fourteen pesticides investigated in this study.

\begin{tabular}{lllllll}
\hline \multirow{2}{*}{ Name } & \multicolumn{2}{c}{ Intra Run } & \multicolumn{2}{c}{ Inter Run } & \multicolumn{2}{c}{ Complete study } \\
\cline { 2 - 7 } & $\begin{array}{l}\text { Accuracy } \\
(\mathbf{n = 4 5})\end{array}$ & $\begin{array}{l}\text { Precision } \\
(\mathbf{n = 4 5})\end{array}$ & $\begin{array}{l}\text { Accuracy } \\
(\mathbf{n = 4 5 )}\end{array}$ & $\begin{array}{l}\text { Precision } \\
(\mathbf{n = 4 5})\end{array}$ & $\begin{array}{l}\text { Accuracy } \\
(\mathbf{n = 2 2 5})\end{array}$ & $\begin{array}{l}\text { Precision } \\
(\mathbf{n}=\mathbf{2 2 5})\end{array}$ \\
\hline Aminocarb & 99.1 & 4.0 & 100.4 & 4.1 & 100.4 & 6.5 \\
Atrazine & 100.2 & 4.2 & 101.5 & 3.2 & 100.7 & 5.8 \\
Carbofuran & 100.7 & 5.0 & 101.8 & 4.2 & 101.0 & 6.1 \\
Diazinon & 105.1 & 13.3 & 105.5 & 13.8 & 105.0 & 15.8 \\
Dimethoate & 98.1 & 3.8 & 99.9 & 3.6 & 100.1 & 7.1 \\
Imazalil & 100.8 & 4.8 & 101.7 & 4.6 & 100.9 & 5.3 \\
Imazapyr & 101.1 & 5.2 & 101.5 & 4.2 & 100.9 & 6.4 \\
Malathion & 99.6 & 5.1 & 100.1 & 4.6 & 100.1 & 7.4 \\
Metazachlor & 100.0 & 3.6 & 100.7 & 3.1 & 100.4 & 5.4 \\
Metosulam & 100.5 & 4.3 & 100.9 & 3.7 & 100.6 & 5.9 \\
Metoxuron & 101.0 & 7.1 & 101.5 & 6.1 & 101.0 & 7.2 \\
Molinate & 99.6 & 10.2 & 99.3 & 6.0 & 99.7 & 10.3 \\
Pyraclostrobin & 100.4 & 7.8 & 100.5 & 9.5 & 98.8 & 16.5 \\
Thiabendazole & 101.4 & 7.2 & 102.3 & 6.8 & 101.5 & 8.3 \\
\hline
\end{tabular}

termined from analysis of a sample in a given matrix containing the analyte. In the present study, a range of pesticide concentrations of $12.5 \mathrm{ng}$ to $1000 \mathrm{ng} / \mathrm{L}$ of water were selected for testing curve fitting and range of the assay. One liter volume of water was used for extraction, eluted pesticides made up to ten $\mathrm{ml}$ with water, and a $10 \mu \mathrm{L}$ injection was made, thus effectively giving rise to $12.5 \mathrm{pg}$ on column quantity for the lowest concentration studied. LOD, LOQ and MDL were calculated (Table 6$)$ from replicate analysis $(n=5)$ of lowest concentration level $(12.5 \mathrm{ng} / \mathrm{L})$ of pesticides using Mass Hunter software (B.07). Different pesticides exhibited different values for LOD and MDL, since ionization behaviour is largely controlled by physicochemical properties of the molecule and matrix interactions. Pesticides with basic functional groups exhibited lower method detection limits of 0.6 to $2.4 \mathrm{ng} / \mathrm{L}$ of water which translated into a theoretical limit of quantitation of 1.6 to $6.5 \mathrm{ng} / \mathrm{L}$ of water; whereas the pesticides lacking basic functional groups, i.e. malathion and molinate had method detection limit of 4.1 and $5.9 \mathrm{ng} / \mathrm{L}$ leading to a theoretical limit of quantitation of 10.9 and $15.8 \mathrm{ng} / \mathrm{L}$. However experimentally we were able to quantitate molinate with very good accuracy (98.15) and precision (\%RSD 8.1). It may be noted that molinate does contain a nitrogen atom but presence of a keto function next to nitrogen atom causes delocalization of loan pair of nitrogen resulting in loss of basicity which coupled with semi-volatile behaviour of molinate translates into relatively higher limit of quantitation. Carbofuran has similar functional features, but the presence of an oxygen atom with two methyl groups 


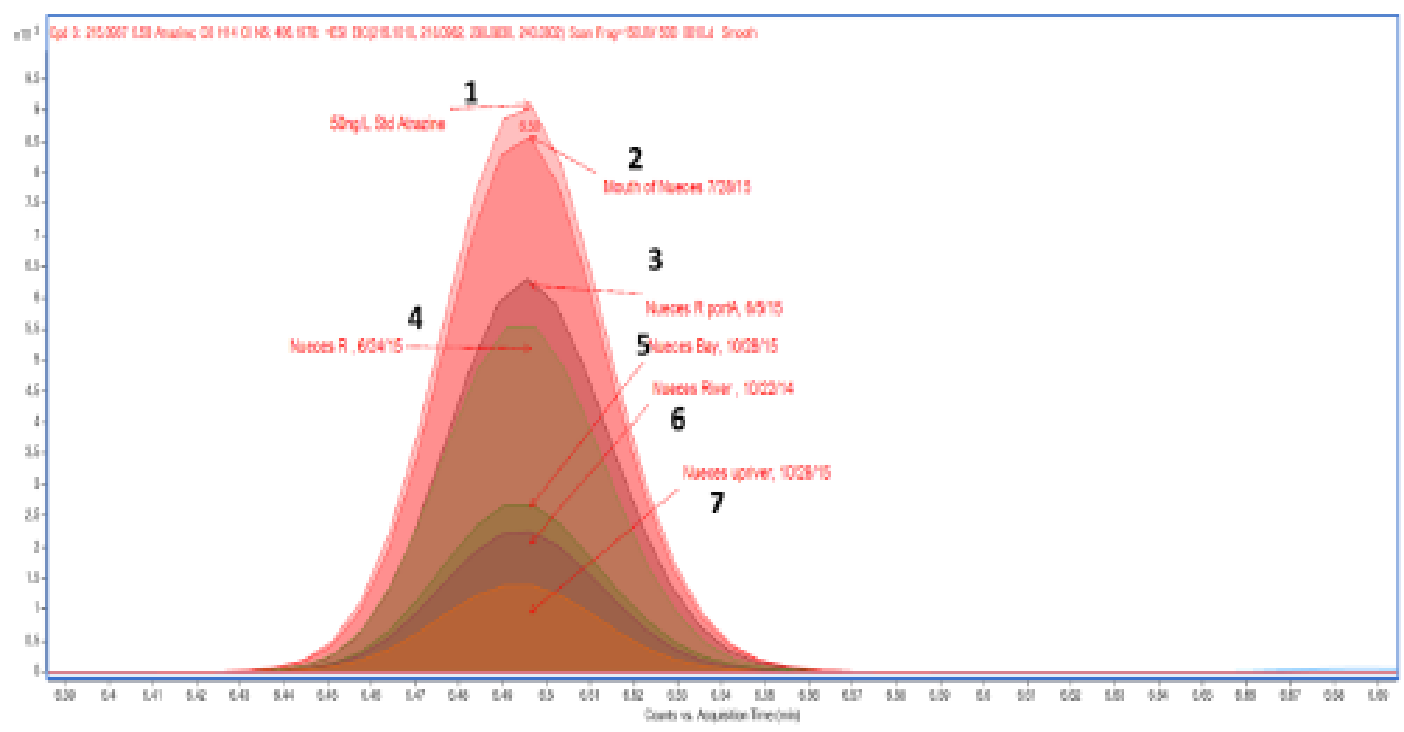

Fig. 6. Determination of atrazine in Nueces river water collected at different location along the river. 1: Atrazine standard $500 \mathrm{ng} / \mathrm{L} ; 2$ : Water collected at the mouth of the Nueces River; 3: Water collected at Nueces River port; 4: Water collected from Nueces River on 24 ${ }^{\text {th }}$ June 2015; 5: Water collected at Nueces River Bay; 6: Water collected from Nueces River on $22^{\text {nd }}$ October 2014; 7: Water collected Nueces upriver. Complete analytical details are given in experimental section.

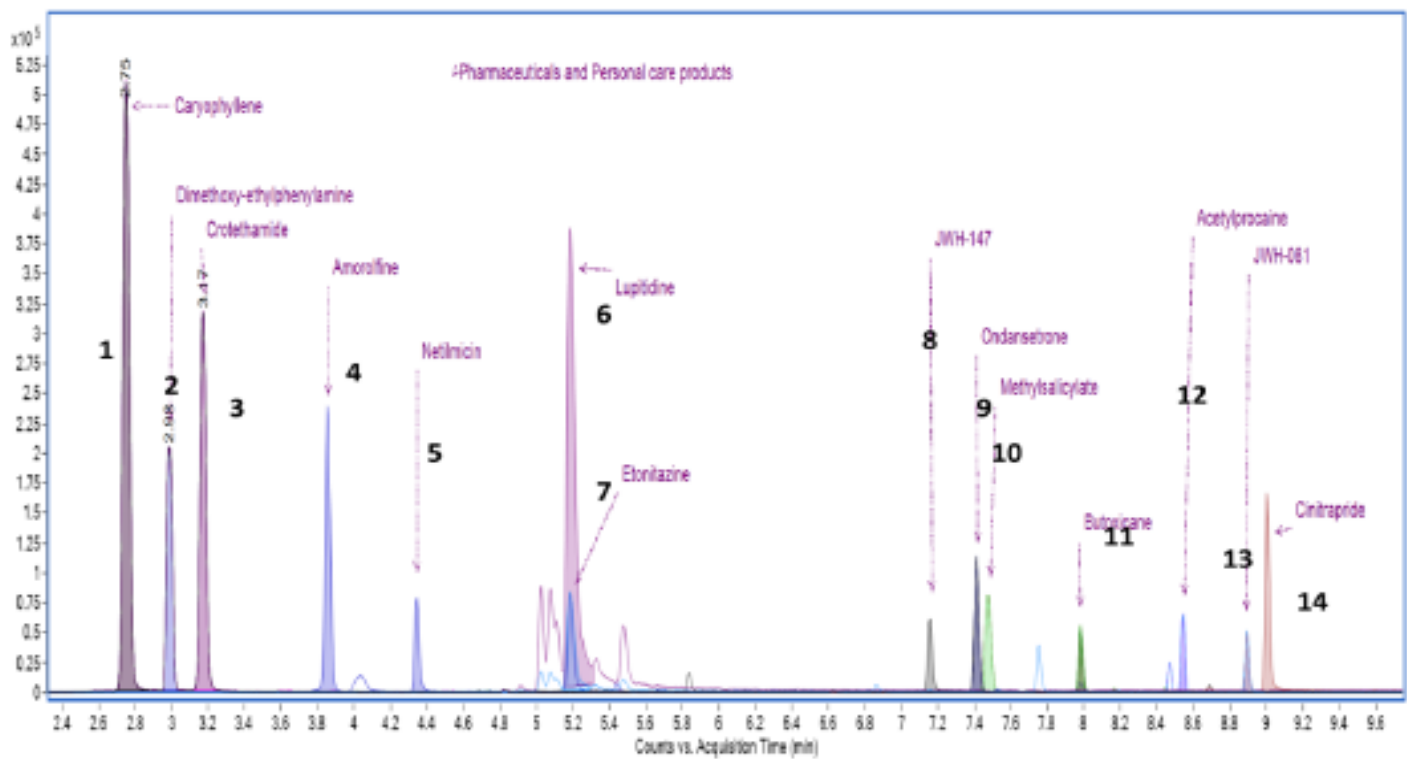

Fig. 7. Non-targeted analysis of Pharmaceuticals and personal care products (PCPs) in the waters of Nueces River, Texas, USA. 1: Carryophyllene; 2: Dimethoxyethylphenylamine; 3:Crotheamide; 4: Amorolfine; 5: Netilmicin; 6: Lupitidine; 7: Etonitazine; 8: JWH-147; 9: Ondansetrone; 10: Methyl Salicylate; 11: Butoxicaine; 12: Acetylprocaine; 13: JWH-081; 14: Cinitrapride. Complete analytical details are given in experimental section.

(+Inductive effect) seem to compensate for the loss of basicity resulting into better $\mathrm{LOQ}$ and MDL values. Therefore, the limit of quantitation was 1.6 to $12.5 \mathrm{pg}$ of pesticides on a column or in more mundane terms was 1.6 to $12.5 \mathrm{ng} / \mathrm{L}$ or 1.6 to 12.5 parts per trillion (ppt).

Robustness and ruggedness: The robustness and ruggedness of the method were evaluated by introducing small, deliberate changes in extraction procedure and LC-MS conditions. Robustness was assessed early in the development of the method. As mentioned earlier, we studied several different kinds of cartridges for the extraction of pesticides. Waters Oasis HLB 6 cc and Phenomenex Strata-X 6 cc cartridges with the polymeric sorbent, were found to be suitable for this work (Table 4). The present SPE method did not require any nitrogen evaporation and reconstitution of samples, which had a beneficial impact on the analysis of liquids and volatile/semi-volatile compounds such as molinate and malathion. SPE method also provided extraction of polar compounds such as aminocarb , non-polars such as mollinate, malathione, diazinone, 
Table 6. Limit of Detection (LOD) and Limit of Quantitation (LOQ) and Method Detection Limit (MDL) calculated from replicate analysis of. $12.5 \mathrm{ng} / \mathrm{L}$ concentration level.

\begin{tabular}{lllllll}
\hline Name & {$[\mathbf{M + H}]+$} & MDL & LOQ & LOD & S/N & $\begin{array}{l}\text { Response } \% \\
\text { RSD }\end{array}$ \\
\hline Aminocarb & 209.1285 & 1.2 & 3.1 & 0.9 & $\infty$ & 2.5 \\
Atrazine & 216.101 & 1.7 & 4.4 & 1.3 & 14 & 3.5 \\
Carbofuran & 222.1125 & 0.9 & 2.5 & 0.7 & 15 & 2 \\
Diazinon & 305.1083 & 2.4 & 6.3 & 1.9 & 23 & 5.1 \\
Dimethoate & 230.0069 & 1.9 & 5.0 & 1.5 & 6 & 4 \\
Imazalil & 297.0556 & 0.6 & 1.6 & 0.5 & 19 & 1.2 \\
Imazapyr & 262.1186 & 0.6 & 1.7 & 0.5 & 47 & 1.4 \\
Malathion & 331.0433 & 4.1 & 10.9 & 3.3 & 10 & 8.7 \\
Metazachlor & 278.1055 & 0.7 & 2.0 & 0.6 & $\infty$ & 1.6 \\
Metosulam & 418.0138 & 0.8 & 2.1 & 0.6 & 21 & 1.7 \\
Metoxuron & 229.0738 & 1.4 & 3.7 & 1.1 & 29 & 3 \\
Molinate & 188.1104 & 5.9 & 15.8 & 4.7 & $\infty$ & 12.6 \\
Pyraclostrobin & 388.1059 & 1.9 & 5.0 & 1.5 & 16 & 4 \\
Thiabendazole & 202.0433 & 0.9 & 2.4 & 0.7 & 38 & 1.9 \\
\hline
\end{tabular}

Table 7. Analysis of fourteen pesticides on four different Chromatographic columns.

\begin{tabular}{lcccccccc}
\hline \multirow{3}{*}{ Compound } & \multicolumn{2}{c}{ Column zero } & \multicolumn{2}{c}{ Column One } & \multicolumn{2}{c}{ Column Two } & \multicolumn{2}{c}{ Column Three } \\
\cline { 2 - 9 } & Accuracy & tR & Accuracy & tR & Accuracy & tR & Accuracy & tR \\
& (\%RSD) & (\%RSD) & (\%RSD) & (\%RSD) & (\%RSD) & (\%RSD) & (\%RSD) & (\%RSD) \\
\hline Aminocarb & $98.7(4.7)$ & $2.3(0.4)$ & $99.9(5.4)$ & $1.41(0.3)$ & $99.7(5.2)$ & $1.91(0.2)$ & $101.1(6.0)$ & $2.34(0.2)$ \\
Atrazine & $100.4(3.7)$ & $6.5(0.1)$ & $96.5(6.5)$ & $5.28(0.0)$ & $99.5(2.9)$ & $5.65(0.0)$ & $99.9(4.6)$ & $6.25(0.0)$ \\
Carbofuran & $100.9(4.2)$ & $5.8(0.1)$ & $99.8(5.3)$ & $4.64(0.1)$ & $100.3(3.7)$ & $5.02(0.1)$ & $100.0(6.9)$ & $5.84(0.1)$ \\
Diazinon & $106.4(13.4)$ & $8.1(0.0)$ & $105.8(14.0)$ & $7.09(0.0)$ & $106.4(15.6)$ & $7.17(0.1)$ & $105.9(14.0)$ & $7.09(0.0)$ \\
Dimethoate & $99.6(4.5)$ & $4.2(0.1)$ & $96.2(6.3)$ & $3.01(0.1)$ & $100.5(4.3)$ & $3.50(0.0)$ & $99.7(4.0)$ & $4.47(0.0)$ \\
Imazalil & $101.1(4.5)$ & $6.3(0.0)$ & $100.3(4.3)$ & $5.07(0.1)$ & $100.1(3.9)$ & $5.47(0.0)$ & $100.8(7.5)$ & $6.39(0.1)$ \\
Imazapyr & $101.1(4.9)$ & $4.0(0.0)$ & $100.4(4.1)$ & $2.93(0.0)$ & $95.7(8.9)$ & $3.49(0.1)$ & $95.4(9.9)$ & $4.00(0.1)$ \\
Malathion & $99.4(4.0)$ & $7.3(0.0)$ & $99.6(6.6)$ & $6.27(0.0)$ & $99.5(4.5)$ & $6.46(0.1)$ & $98.8(4.1)$ & $7.46(0.0)$ \\
Metazachlor & $100.2(3.2)$ & $6.5(0.0)$ & $99.2(4.6)$ & $5.43(0.1)$ & $99.1(3.9)$ & $5.78(0.1)$ & $99.8(6.5)$ & $6.71(0.0)$ \\
Metosulam & $100.8(4.1)$ & $5.9(0.0)$ & $99.4(4.6)$ & $4.88(0.0)$ & $99.2(7.3)$ & $5.35(0.0)$ & $100.0(5.7)$ & $6.52(0.0)$ \\
Metoxuron & $101.4(6.7)$ & $5.1(0.1)$ & $100.2(5.8)$ & $3.94(0.1)$ & $98.2(7.5)$ & $4.38(0.0)$ & $99.1(7.9)$ & $5.25(0.0)$ \\
Molinate & $100.3(11.8)$ & $7.5(0.0)$ & $99.2(9.4)$ & $6.28(0.1)$ & $100.2(5.7)$ & $6.47(0.1)$ & $99.0(12.7)$ & $7.22(0.0)$ \\
Pyraclostrobin & $100.8(8.9)$ & $8.2(0.0)$ & $98.8(8.7)$ & $7.19(0.0)$ & $98.6(8.3)$ & $7.24(0.0)$ & $99.5(8.5)$ & $8.33(0.0)$ \\
Thiabendazole & $101.6(6.5)$ & $3.6(0.2)$ & $101.0(6.0)$ & $2.46(0.0)$ & $100.7(4.6)$ & $3.11(0.1)$ & $100.9(7.4)$ & $3.63(0.1)$ \\
\hline
\end{tabular}

Column Zero: Poroshell $120 \mathrm{EC}, \mathrm{C}_{18}, 2.7 \mathrm{~mm}, 2.1 \times 150 \mathrm{~mm} ; \mathrm{r}^{2}=0.997, \% R S D 0.3$; Column One: Zorabax Eclipse plus $\mathrm{C}_{8}, \mathrm{RRHD}, 1.8$ $\mathrm{mm}, 2.1 \times 50 \mathrm{~mm} ; \mathrm{r}^{2}=0.996$, \%RSD 0.5; Column Two: Poroshell $120 \mathrm{SB}, \mathrm{C}_{8}, 2.7 \mathrm{~mm}, 2.1 \times 100 \mathrm{~mm} ; \mathrm{r}^{2}=0.999$, \%RSD 0.1; Column Three: Poroshell 120 Phenyl hexyl, $2.7 \mathrm{~mm}, 2.1 \times 150 \mathrm{~mm} ; \mathrm{r}^{2}=0.997, \%$ RSD 0.4 .

pyraclostrobin, and amphoteric compound such as Imazapyr. We studied several HPLC columns for the resolution and quantitation of pesticides. The method developed for the analysis of pesticides in environmental water was robust and rugged and was not affected by a) the use of water from different locations, b) the use of columns of different dimensions ranging from $50 \mathrm{~mm}$ to $150 \mathrm{~mm}$ in length and 2.1 to $4.6 \mathrm{~mm}$ in internal diameter and d) use of different bonded phases $\mathrm{C}_{18}$ vs $\mathrm{C}_{8}$ vs hexyl phenyl columns (Table 7 ).

In the present study, the freeze-thaw stability of pesticides was assessed in spiked samples at three concentration levels $(25,100$ and $500 \mathrm{ng} / \mathrm{L})$. Spiked samples prepared at three concentration levels were subjected to repeated (three times) freeze-thaw cycles. The samples were analyzed against a freshly pre- 
Table 8. Recovery of fourteen pesticides after three freeze-thaw cycles.

\begin{tabular}{lll}
\hline Compound & Accuracy & \%RSD \\
\hline Aminocarb & 101.5 & 9.6 \\
Atrazine & 101.9 & 6.7 \\
Carbofuran & 101.1 & 4.6 \\
Diazinon & 101.9 & 10.9 \\
Dimethoate & 103.6 & 11.5 \\
Imazalil & 100.1 & 5.0 \\
Imazapyr & 101.9 & 7.1 \\
Malathion & 102.1 & 13.2 \\
Metazachlor & 99.7 & 5.6 \\
Metosulam & 102.3 & 6.8 \\
Metoxuron & 101.1 & 5.1 \\
Molinate & 107.6 & 15.6 \\
Pyraclostrobin & 100.6 & 11.3 \\
Thiabendazole & 100.8 & 6.8 \\
\hline
\end{tabular}

pared calibration curve. Each determination was performed in triplicate. Three freeze-thaw cycles were tolerated without any significant change in pesticide concentrations. The average recoveries of the fourteen pesticides were between 99 and 108\% (\%RSD 5 to $16 \%$, Table 8 ).

All lons MS/MS technique provided an easy approach to set up qualitative acquisition methods on a TOF instrument; quickly confirming the identities of compounds with high-resolution accurate mass data and fragments using commercial or in a house built databases. The quantitative methods could be set up in a few minutes without knowing fragment ions. All lons MS/MS allowed screening of hundreds of compounds in a single analysis since no prior knowledge of optimization of compounds was required. It is limited by ionization behaviour, an inherent property of the molecule in question and good chromatography which implies for non-isobaric compounds symmetrical sharp peaks not necessarily completely resolved.

The method was successfully used to study the presence of various compounds present in environmental waters of Corpus Christi area of Texas, USA. Water samples collected from Nueces River, Texas, USA were processed and analyzed using three fragmentor voltages as discussed earlier and then studied against pesticide database which revealed the presence of more than a dozen pesticides in water (Fig. 5). Determination of atrazine in Nueces river water, collected at different locations and timings of the year is shown in Fig. 6, by including a sample of atrazine at $500 \mathrm{ng} / \mathrm{L}$ concentration, the results could be analyzed semiquantitatively. The same data files were then analyzed against accurate mass databases of pharmaceuticals and personal care products to reveal the presence of another more than a dozen compounds (Fig. 7). Understandably the final confirmation will rest with the fragmentation patterns and matching retention times followed by quantitative analysis, but no doubt a strong beginning had been achieved.

Mass spectrometry is being increasingly used in doping and forensic analysis (Remane et al. 2016; Schänzer, and Thevis, 2015). It is well known that forensic and anti-doping laboratories regularly use strategies based on targeted analysis of compounds which means that only targeted compounds can be analyzed. The real challenges lie beyond the anticipation of known molecular targets, such as the detection of designer drugs (Sardela et al., 2019). This technique of acquiring data at more than one fragmentor voltages will be very helpful in the analysis of designer derivatives of banned substances such as anabolic steroids, $\beta-2$ agonists, diuretics etc. which routinely escape analysis by triple quadruple ( $Q Q Q)$ mass spectrometers.

\section{Conclusion}

Use of three different fragmentor voltages (low, medium and high) enabled the qualitative and quantitative analysis of a diverse range of targeted organic compounds using liquid chromatography-time of flight mass spectrometer in environmental waters. The technique has been illustrated with reference to a group of pesticides having diverse chromatographic and ionization behaviour. No prior optimization of each and every compound being quantified was required. Same data file could be subjected to repeated post-run data analysis to figure out the presence of non-targeted compounds. This technique will be immensely useful in the analysis of designer derivatives of banned substances such as anabolic steroids, $\beta-2$ agonists, diuretics etc.

\section{REFERENCES}

1. Alder, L., Greulich, K., Kempe, G., and Vieth, B. (2006). Residue analysis of 500 high priority pesticides: Better by GC-MS or LC-MS/MS? Mass Spectrom. Rev. 25(6), 838 -865. doi:10.1 002/mas.20091.

2. Amelin, V. G., and Andoralov, A. M. (2015). Highperformance liquid chromatography-time-of-flight mass spectrometry in the identification and determination of 111 pesticides in food, feed, water, and soil. J. Anal. Chem. 71 (1), 82-93. doi:10.1134/s1061934815120035.

3. Arsand, J. B., Hoff, R. B., Jank, L., Dallegrave, A., Galeazzi, C., Barreto, F., and Pizzolato, T. M. (2018). WideScope Determination of Pharmaceuticals and Pesticides in Water Samples: Qualitative and Confirmatory Screening Method Using LC-qTOF-MS. Water, Air, \& Soil Pollution, 229(12), 399. doi:10.1007/s11270-018-4036-2.

4. Botero-Coy, A. M., Marín, J. M., Ibáñez, M., Sancho, J. V., and Hernández, F. (2011). Multi-residue determination of pesticides in tropical fruits using liquid chromatography/ tandem mass spectrometry. Anal. Bioanal. Chem. 402(7), 2287-2300. doi:10.1007/s00216-011-5431-3.

5. Botitsi, H. V., Garbis, S. D., Economou, A., and Tsipi, D. F. (2010). Current mass spectrometry strategies for the 
analysis of pesticides and their metabolites in food and water matrices. Mass Spectrom. Rev. 30, 907- 939. doi:10.1002/mas.20307.

6. Cotton, J., Leroux, F., Broudin, S., Poirel, M., Corman, B., Junot, C. and Ducruix, C. (2016). Development and validation of a multiresidue method for the analysis of more than 500 pesticides and drugs in water based on on-line and liquid chromatography coupled to high resolution mass spectrometry. Water Research, 104: 20-27. doi:10.1016/j.watres.2016.0 7.0 75.

7. Elbashir, A. A., and Aboul-Enein, H. Y. (2017). Application of gas and liquid chromatography coupled to time-of-flight mass spectrometry in pesticides: Multiresidue analysis. Biomed. Chromatog., 32(2), e4038. doi:10.1002/ bmc.4038.

8. Gago-Ferrero, P., Bletsou, A. A., Damalas, D. E., Aalizadeh, R., Alygizakis, N. A., Singer, H. P., and Thomaidis, N. S. (2019). Wide-scope target screening of $>2000$ emerging contaminants in wastewater samples with UPLC -Q-TOF-HRMS/MS and smart evaluation of its performance through the validation of 195 selected representative analytes. J. Hazardous Materials, 121712. doi:10.1016/j.jhazma t.2019.121712.

9. Gao, L., Qin, D., Huang, X., Wu, S., Chen, Z., Tang, S., \& Wang, P. (2019). Determination of pesticides and Pharmaceuticals from Fish Cultivation Water by parallel solidphase extraction (SPE) and liquid chromatographyquadrupole time-of-flight mass spectrometry. Anal. Letters, 52: 1-15. doi:10.1080/00032719.2018.150907 6.

10.Holcapek, M. and Byrdwell, W.C. (2017) Eds. Handbook of Advanced Chromatography/Mass Spectrometry Techniques. Academic. Press London, UK.

11.Jaikwang, P., Junkuy, A., Ratana Sapbamrer, R., Seesen, M., Khacha-ananda, S., Mueangkhiao, P. and Wunnapuk, K. (2020). A Dilute-and-Shoot LC-MS/MS Method for Urinary Glyphosate and AMPA. Chromatographia Pub Date: 2020-01-08, DOI: 10.1007/s10337-019-03853-3.

12.Kharbouche, L., Gil García, M. D., Lozano, A., Hamaizi, H., and Galera, M. M. (2019). Solid phase extraction of pesticides from environmental waters using an MSU-1 mesoporous material and determination by UPLC-MS/MS. Talanta, 199, 612-619. doi:10.1016/j.talant a.2019.0 2.092.

13.Latrous El Atrache, L., Ben Sghaier, R., Bejaoui Kefi, B., Haldys, V., Dachraoui, M., and Tortajada, J. (2013). Factorial design optimization of experimental variables in preconcentration of carbamates pesticides in water samples using solid phase extraction and liquid chromatographyelectrospray-mass spectrometry determination. Talanta, 117, 392-398. doi:10.101 6/j.tal an ta.20 13.09.032.

14.Lee, H.-J., Kadokami, K., and Oh, J.-E. (2020). Occurrences of microorganic pollutants in the Kumho River by a comprehensive target analysis using LC-Q/TOF-MS with sequential window acquisition of all theoretical fragment ion spectra (SWATH). Sci. Total Environ. 136508. doi:10.1016/j.scitotenv.2020.136 508.

15.Marwah, P., \& Marwah, A. (2013). Ion funnel quadrupole time of Flight mass spectrometry: optimization for achieving all ion MS/MS and pseudo MS ${ }^{n}$. J. App. Nat. Sci., 5(1), 242-249. https://doi.org/10.31018/jans.v5i1.313.

16.Marwah, P., Marwah, A. and Zimba, P. (2020). Controlling formation of metal ion adducts and enhancing sensitivity in Liquid Chromatography Mass Spectrometry. J. Appl. Nat. Sci. 12(2), 180-192.https://doi.org/10.31018/jans.v12 i2.22 77.

17.Masiá, A., Ibáñez, M., Blasco, C., Sancho, J.V., Picó, Y. and Hernández, F. (2013)Combined use of liquid chromatography triple quadrupole mass spectrometry and liquid chromatography quadrupole time-of-flight mass spectrometry in systematic screening of pesticides and other contaminants in water samples. Anal Chim Acta. 761:117127. doi:10.1016/j.aca.20 12.1 1.032.

18.Primel, E., Caldas, S., and Escarrone, A. (2012). Multiresidue analytical methods for the determination of pesticides and PPCPs in water by LC-MS/MS: a review. Open Chemistry, 10(3) 876-899. doi:10.2478/s11532-012-0028z.

19.Remane, D., Wissenbach, D. K., and Peters, F. T. (2016). Recent advances of liquid chromatography-(tandem) mass spectrometry in clinical and forensic toxicology An update. Clin. Biochem., 49(13-14), 1051-1071. doi:10.1016/j.clinbiochem.2016.07.010.

20.Rousis, N. I., Bade, R., Bijlsma, L., Zuccato, E., Sancho, J. V., Hernandez, F., and Castiglioni, S. (2017). Monitoring a large number of pesticides and transformation products in water samples from Spain and Italy. Environ. Res., 156, 31-38. doi:10.1016/j.envres.2017.03.013.

21.Sabik, H., Jeannot, R., and Rondeau, B. (2000). Multiresidue methods using solid-phase extraction techniques for monitoring priority pesticides, including triazines and degradation products, in ground and surface waters. J. Chromatog. A, 885(1-2), 217-236. doi:10.1016/s0021-9673(99) 01084-5.

22.Sardela, P. D. de O., Sardela, V. F., da Silva, A. M. dos S., Pereira, H. M. G., and de Aquino Neto, F. R. (2019). A pilot study of non-targeted screening for stimulant misuse using high-resolution mass spectrometry. Forensic Toxicology. doi:10.1007/s11419-019-00482-1.

23.Schänzer, W., and Thevis, M. (2015). Human sports drug testing by mass spectrometry. Mass Spectrom. Rev., 36 (1), 16-46. doi:10.1002/mas.21479.

24.Sidhu, G. K., Singh, S., Kumar, V., Dhanjal, D. S., Datta, S., and Singh, J. (2019). Toxicity, monitoring and biodegradation of organophosphate pesticides: A review. Crit. Reviews Enviro. Sci. Techn., 1-53. doi:10.1080/1064338 9.2019.1565554.

25.Siuzdak, G. (2003). The Expanding role of mass spectrometry in Biotechnology. MCC Press, San Diego USA

26.Tankiewicz, M., Fenik, J., \& Biziuk, M. (2011). Solvent less and solvent-minimized sample preparation techniques for determining currently used pesticides in water samples: A review. Talanta, 86, 8-22. doi:10.1016/ j.talanta.2011.0 8.056. 